\title{
Fundamental motor skills in the first year of school: Associations with prematurity and disability
}

\author{
Viviene Anne Temple ${ }^{1}$, Danielle Guerra ${ }^{1}$, Lizette Larocque ${ }^{1}$, Jeff R. Crane ${ }^{1}$, Erin Sloan ${ }^{2}$, \\ and Lynneth Stuart-Hill ${ }^{1}$
}

${ }^{1}$ University of Victoria, Victoria, British Columbia, Canada; and ${ }^{2}$ Vancouver Island Health Authority, Victoria, British Columbia, Canada

\begin{abstract}
Given the importance of fundamental motor skill proficiency for children's participation in games, sports, and physical activity; our aim was to concurrently examine the fundamental motor skill proficiency of children living with a disability, children born prematurely, and children born full-term without a disability in their first year of school (kindergarten). Participants were 260 children (mean age $=5 \mathrm{y} 9 \mathrm{~m}$; boys $=52 \%$ ); 33 were born prematurely and 12 children lived with a disability. Motor skills were assessed during physical education using the Test of Gross Motor Development-2, and parent reports were used to indicate disability and prematurity status. The motor skill proficiency of all children was quite low; with mean percentile ranks ranging between $<1^{\text {st }}$ and $16^{\text {th }}$ percentile for locomotor skills and the $1^{\text {st }}$ and $16^{\text {th }}$ percentile for object control skills. An analysis of variance showed a significant overall effect and a main effect for disability on the gross motor quotient; but there was no main effect for prematurity, nor interaction between prematurity and disability. The vast majority of the children in this study would benefit from a concentrated effort to enhance motor skills; and this was especially true for children with disabilities.
\end{abstract}

Keywords: early childhood, physical development, delay

\section{Introduction}

To improve cardiorespiratory, musculoskeletal, and metabolic health biomarkers, the World Health Organization (WHO) recommends that children and youth aged 5-17 years accumulate at least one-hour per day of moderate- to vigorous-intensity physical activity, and muscle and bone strengthening activities at least three times per week. These recommendations are made for all children, including children with disabilities. The WHO suggests that children can meet these guidelines by participating in play, games, sports, recreation, and physical education activities. An antecedent for participating in these types of physical activities is fundamental motor skill proficiency (Crane, Naylor, Cook, \& Temple, 2015; Stodden et al., 2008; Temple, Crane, Brown, Williams, \& Bell, 2016); that is, fundamental motor skills are the 'tools' to participate with. We also know that participation in physical activities during early childhood stimulates the perceptual, nervous, and muscular systems to interact more efficiently, thus promoting the development of motor skills (Berger \& Adolph, 2007; Payne \& Issacs, 2008; Stodden et al., 2008). This reciprocal relationship between motor skill development and physically active play is a unique and important feature of the early childhood period (Stodden et al., 2008).

Young children with higher levels of gross motor skill proficiency are more likely to participate in more, and more vigorous, physical activity (Crane et al., 2015; Fisher et al., 2005; Rudisill et al., 2001; Williams et al., 2008), engage in social play (Bar-Haim $\&$ Bart, 2006), have positive perceptions of their physical competence (Bart, Hajami, \& Bar-Haim, 2007; LeGear et al., 2012), and display pro-social behaviour (Bart et al., 2007). Conversely, lower gross motor skill proficiency among young children is associated with social reticence (Bar-Haim \& Bart, 2006), difficulty transitioning to formal schooling (Bart et al., 2007), negative social behaviour and anxiety (Bart et al., 2007), and avoidance or withdrawal from everyday play and sport activities (Valentini \& Rudisill, 2004).

Understanding physical development during the early years can inform the design of programs (Iivonen \& Sääkslahti, 2014) and help with the transition from the preschool to school environment (Margetts, 2002). As Margetts notes, children encounter many "...academic, physical, and social and emotional challenges of commencing school" (Margetts, 2002, p. 104); and understanding the diversity 
of children's needs is key in supporting children's transition to school. However, oftentimes the needs of diverse learners in the motor domain and/or physical education context are not identified or the needs of 'special populations' are examined separately. For example, a recent review of the factors associated with preschool children's fundamental motor skills, specifically excluded studies focusing on 'non-typically developing children' (Iivonen \& Sääkslahti, 2014). Therefore the impact of impairments and health conditions could not be identified as significant individual-level factors in that review; nor subsequently inform future program designs. For the present study, intact kindergarten classes were recruited from inclusive classrooms; with the children's parents indicating whether their child was born prematurely or not, and/ or whether their child had a disability (or health condition) or not.

\section{Preterm birth, disability and motor skills}

Preterm birth, defined as less than 37 completed weeks of gestation (Lawn, Gravett, Nunes, Rubens, \& Stanton, 2010), is associated with neonatal mortality and morbidity (Beck et al., 2010; Health Canada, 2003). However, Lawn et al. (2010) suggest that greater differentiation of preterm status i.e. moderately preterm (33-36 completed weeks of gestation), very preterm ( $<32$ weeks) and extremely preterm ( $<28$ weeks), is useful because developmental sequelae vary by weeks of completed gestation. The present study focuses on children born moderately preterm and very preterm as no recruited children were born extremely preterm.

Children born very preterm are more likely to have significant motor impairment that persists throughout childhood than term born peers (de Kieviet, Piek, Aarnoudse-Moens, \& Oosterlaan, 2009; Kerstjens et al., 2011). They also experience higher rates of developmental coordination disorder compared with the general school-age population (Edwards et al., 2011). A synthesis of Movement Assessment Battery for Children (Henderson \& Sugden, 1992) scores in the de Kieviet et al. (2009) systematic review demonstrated that school age children born very preterm have consistently lower balance skill scores (overall effect size $[d]=-.77, p<.001$ ) but similar ball skills $(d=-.34, p=.21)$ when compared with their term-born peers. The same review also demonstrated that at 8-9 years of age, gross motor scores on the Bruininks-Oseretsky Test of Motor Proficiency (Bruininks \& Bruininks, 2005) were lower for children born very preterm compared with term born children $(d=-.53)$. Children born very preterm are also less likely to participate in after-school physical activities (Wocadlo \& Rieger, 2008).

There are very few studies specifically addressing motor development of children born moderately preterm (Stephens \& Vohr, 2009). The available evidence is also mixed. Parent reports at school entry suggest that children born moderately preterm do not have a greater prevalence of problems with gross motor functioning and problem solving, whereas children born very preterm do experience these problems (Kerstjens et al., 2011). Contrastingly, teachers report that seven-year-old children born moderately preterm are at significant risk of educational difficulties in six areas of function (Huddy, Johnson, \& Hope, 2001); including functioning in physical education.

There is strong international evidence that children with disabilities are less active than children with typical development (Frey, Stanish, \& Temple, 2008; Majnemer et al., 2008; Rimmer \& Rowland, 2008; Steele et al., 1996), that children with disabilities tend to be more restricted in their sporting and leisure opportunities (Murphy \& Carbone, 2008; Shikako-Thomas, Majnemer, Law, \& Lach, 2008), and some evidence that motor skill proficiency is related to participation in organized sports (Westendorp, Houwen, Hartman, \& Visscher, 2011). Irrespective of whether motor skill development is an antecedent or outcome of participation, evidence suggests that children with a disability have low levels of motor skill proficiency (Emck, Bosscher, Beek, \& Doreleijers, 2009; Valentini \& Rudisill, 2004; Woodard \& Surburg, 2001). Children with disabilities experience difficulty in motor skill execution (Berkeley, Zittel, Pitney, \& Nichols, 2001; Green et al., 2009; Katz-Leurer, Rotem, Keren, \& Meyer, 2009; Manjiviona \& Prior, 1995; Provost, Heimerl, \& Lopez, 2007) and their skills tend to be less developed than their typically developing peers (Rarick, 1980; Simons et al., 2008; Westendorp et al., 2011). However, little of this evidence is derived from intact classes that teachers typically teach and need to plan for. Researchers tend to recruit groups of children with a particular disability then compare their skills to peers without a disability (for example, Westendorp et al., 2011; Woodard \& Surburg, 2001) or to normative data (for example, Simons et al., 2008), or describe the children's skills in isolation (for example, Valentini \& Rudisill, 2004).

Given the importance of fundamental motor skill proficiency for children's participation in games, sports, and physical activity; our aim was to concurrently examine the fundamental motor skill proficiency of children living with a disability, children 
born prematurely, and children born full-term without a disability in their first year of school (kindergarten). The interaction between prematurity and disability was also investigated. We hypothesized that the fundamental motor skill proficiency of children born prematurely who did not have a disabling condition would not be different from children born full-term without a disabling condition. We further hypothesized that children with a disabling condition would exhibit significantly lower motor skill proficiency than children born prematurely or full-term without a disabling condition.

\section{Method}

A comparative research design was used to examine differences in motor skill proficiency of typically developing children born to term, children born prematurely, and children living with a disability.

\section{Participants}

Kindergarten children from two schools in one school district in British Columbia, Canada were eligible to participate. The Early Development Index (EDI; Kershaw, Irwin, Trafford, \& Hertzman, 2005) was used to characterize the school readiness of the kindergarten children in this particular school district compared to other school districts in British Columbia. Using the EDI, it was apparent that rates of Physical Health and Well Being, Social Competence, Emotional Maturity, Language and Cognitive Development, and Communication Skills, were higher than or equivalent to, provincial rates (Kershaw et al., 2005). Two-hundred and sixty seven kindergarten children were recruited. Three children chose not to complete the motor skills assessment, two children moved to another school during the study, one child was absent during testing and follow-up testing, and data were incomplete for one child; consequently the final sample was 260 children (boys: $n=136$, mean age $=5.7 \pm 0.3$ years; girls: $n=124$, mean age $=5.8 \pm 0.3$ years). This represented $78 \%$ of the Kindergarten children enrolled in the eight schools. Approval for this study was granted by the University Human Research Ethics Board and the school district. Written informed consent was obtained from parents and children provided assent.

\section{Measures and procedures}

Fundamental motor skill proficiency was assessed using the Test of Gross Motor Development - 2 (TGMD-2; Ulrich, 2000) and a stork stand. The TGMD-2 is a criterion- and norm-referenced test that is used to assess the motor skill development of children between the ages of 3 and 10 years. The TGMD-2 was used to assess the children's fundamental motor skills (specifically locomotor and object control skills) and to provide an estimate of each child's current gross motor development (the gross motor quotient). The range of possible raw scores for object control and locomotor skills was $0-48$. Gross motor quotient scores may range from 46-160 $[M=100, S D=15]$ (Ulrich, 2000). Additionally, we assessed one non-locomotor skill, the stork stand. The stork stand was performed on the right foot twice and the left foot twice. Each child was timed standing on one foot with the sole of their other foot against the side of their supporting knee with hands on hips and their eyes open. Children held this position for as long as possible or a maximum of 30 -seconds.

Each kindergarten class was divided into four small groups (3-5 children) these groups rotated around four stations and completed 3-4 skills per station during scheduled physical education lessons. A team of trained research assistant (graduate and undergraduate students) administered the TGMD-2 and the stork stand. For the TGMD-2 skills, one research assistant operated the camera and one demonstrated each skill and administered the test. Digital video was used to record the children performing six locomotor skills (run, jump, hop, slide, gallop, and leap) and six object control skills (throw, roll, kick, strike, catch, and bounce). Children were also timed while performing the stork stand. Demographic information was obtained from parents via a brief survey attached to the consent materials. Parents were asked to indicate whether their child had a disability or health condition (dichotomous i.e. 'Yes or No') and if 'Yes' to describe the condition/disability. Parents were also asked whether their child was born prematurely (dichotomous i.e. 'Yes or No') and if 'Yes' to indicate the number of weeks premature.

\section{Data treatment and analyses}

The behavioral components of object control skills, locomotor skills, and the dodge were scored dichotomously by the investigators; 0 or 1 depending on whether the component was completed correctly. The Percent Agreement Method [Number of Agreements/(Number of Agreements + Disagreements) $\times$ 100] (Zarrett et al., 2009) was used to examine inter-observer reliability. We aimed to assess a minimum of $15 \%$ of the video recordings from each class. In total, $17.6 \%$ of the video were coded by two 
investigators. Percent agreement ranged from $80.2 \%$ to $94.8 \%$, with a mean of $87.8 \%$.

Mean and median scores were computed for the locomotor skill and object control skill subtests of the TGMD-2. Additionally, normative percentile ranks and the gross motor quotient were computed using the TGMD-2 Examiner's Manual (Ulrich, 2000). Average times were computed for the right and left foot stork stand. As the TGMD-2 sub-tests scores of some groups had non-normal distributions, the nonparametric Kruskal-Wallis analysis of variance (Salkind \& Rasmussen, 2007) was used to determine if the four sub-groups:

1. not premature and no disability,

2. not premature with disability,

3. premature and no disability

4. and premature with disability; came from the same population.

When the Kruskal-Wallis test indicated that at least one of the sub-groups did not belong to the same population, pairwise contrasts were conducted with adjustment for the number of groups (Langley, 1979). An analysis of variance for the gross motor quotient was computed with disability and prematurity as factors. All analyses were performed using SPSS ${ }^{\circledR} 22$ for Windows (SPSS Inc., 2013).

\section{Results}

Thirty-three children were reported as premature by their parents (born after 28 completed weeks but less than 37 completed weeks of gestation); none of the children were extremely premature. Of the 33 premature children, four boys had a disability: cerebral palsy $(n=1)$; Ehler-Donlos syndrome $(n=1)$; mild autism $(n=1)$; and a fourth child had attention deficit hyperactive disorder, oppositional defiant disorder, and post-traumatic stress disorder. Eight children (boys $=4$, girls $=4$ ) who were not born prematurely had a disability, specifically: visual impairment (boy $=1$, girls $=2$ ), hearing impairment ( girl =1), Syringomyelia ( $\operatorname{girl}=1)$, Developmental Coordination Disorder (boy $=1)$, medium chain acyl-CoA dehydrogenase deficiency (boy $=1$ ), and global developmental delay (boy $=1$ ).

Descriptive statistics for the locomotor and object control raw scores, the gross motor quotient, and the stork stand scores are shown in Table 1. The mean locomotor raw scores reported in Table 1 translate into the following percentile ranks: 16 for not premature and no disability; 5 for not premature with disability; 16 for premature and no disability; and $<1$ for premature with disability. Without breaking down our data by gender, the object control raw scores translate into the following percentile ranks when compared to the male/female normative tables provided by Ulrich (2000): $9 / 16$ for not premature and no disability; $2 / 5$ for not premature with disability; $9 / 9$ for premature and no disability; and $1 / 2$ for premature with disability. The Kruskal-Wallis $\mathrm{H}$ test showed that there was a statistically significant difference in locomotor skills $\chi^{2}(3)=14.476, p=.002$, in object control skills $\chi^{2}(3)=8.776, p=.032$, and stork stand on the right foot $\chi^{2}(3)=8.405, p=.038$; but not for stork stand on the left foot $\chi^{2}(3)=7.617, p=.055$. The results of the pairwise comparisons are shown in Table 1. The analysis of variance with gross motor quotient as the dependent measure showed a significant effect

Table 1

Motor skill performance of children in kindergarten by disability and prematurity status

\begin{tabular}{|c|c|c|c|c|c|c|c|c|c|c|c|c|}
\hline & \multicolumn{6}{|c|}{ Typically Developing (TD) } & \multicolumn{6}{|c|}{ Disability (D) } \\
\hline & \multicolumn{3}{|c|}{$\begin{array}{l}\text { Not Premature (NP) } \\
\quad(n=219)\end{array}$} & \multicolumn{3}{|c|}{$\begin{array}{l}\text { Premature }(\mathrm{P}) \\
\qquad(n=29)\end{array}$} & \multicolumn{3}{|c|}{$\begin{array}{l}\text { Not Premature (NP) } \\
\qquad(n=8)\end{array}$} & \multicolumn{3}{|c|}{$\begin{array}{l}\text { Premature }(\mathrm{P}) \\
\qquad(n=4)\end{array}$} \\
\hline & $M$ & $S D$ & $M d n$ & $M$ & $S D$ & $M d n$ & $M$ & $S D$ & $M d n$ & $M$ & $S D$ & $M d n$ \\
\hline Age (years) & 5.7 & 0.3 & 5.8 & 5.8 & 0.3 & 5.8 & 5.8 & 0.4 & 5.8 & 5.8 & 0.5 & 6.0 \\
\hline Locomotor skills ${ }^{\text {abcd }}$ & 26.5 & 7.0 & 26.0 & 26.1 & 6.7 & 26.0 & 19.6 & 7.9 & 20.5 & 11.5 & 8.7 & 12.5 \\
\hline Object control skills ${ }^{\mathrm{a}}$ & 21.5 & 7.4 & 25.0 & 19.6 & 6.0 & 18.0 & 15.3 & 6.2 & 16.5 & 14.0 & 6.1 & 15.0 \\
\hline Stork stand $-\mathrm{R}(\mathrm{s})^{\mathrm{ac}}$ & 10.1 & 7.0 & 13.8 & 11.2 & 8.2 & 8.5 & 5.1 & 5.6 & 3.0 & 6.7 & 9.7 & 2.8 \\
\hline Stork stand - L (s) & 9.8 & 7.4 & 7.5 & 9.8 & 7.6 & 7.0 & 5.9 & 6.1 & 4.7 & 3.2 & 3.2 & 2.7 \\
\hline Gross Motor Quotient & 80.8 & 13.5 & 82.0 & 77.1 & 12.6 & 80.5 & 67.0 & 15.2 & 68.5 & 56.5 & 11.4 & 52.0 \\
\hline
\end{tabular}

Note. $\quad M=$ mean; $S D=$ standard deviation; $M d n=$ median; ${ }^{\mathrm{a}}=\mathrm{TD}+\mathrm{NP}$ significantly different $p<.05$ from $\mathrm{D}+\mathrm{NP},{ }^{\mathrm{b}}=\mathrm{TD}+\mathrm{NP}$ significantly different $p<.05$ from $\mathrm{D}+\mathrm{P} ;{ }^{c}=\mathrm{TD}+\mathrm{P}$ significantly different $p<.05$ from $\mathrm{D}+\mathrm{NP},{ }^{\mathrm{d}}=\mathrm{TD}+\mathrm{P}$ significantly different $\mathrm{p}<.05$ from $\mathrm{D}+\mathrm{P}$. 
for disability status $F(1,254)=15.75, p<.001$; but no effect for prematurity $F(1,254)=2.64, p=.105$ or interaction between prematurity and disability $(p=.423)$.

\section{Discussion}

This study examined the fundamental motor skill proficiency of children born prematurely and their peers born full-term. We also examined the effect of disability status and the interaction between prematurity and disability on motor skill levels. The results suggest that the motor skill proficiency of all children was quite low; with mean percentile scores based on ageand gender-specific comparisons ranging between less than the $1^{\text {st }}$ and $16^{\text {th }}$ percentile for locomotor skills and the $1^{\text {st }}$ and $16^{\text {th }}$ percentile for object control skills. Descriptive qualifiers of TGMD-2 gross motor quotient scores (Ulrich, 2000) denote that scores of 80-89 are "below average", and score of 70-79 are "poor". In this study, $75 \%$ of the children's gross motor quotients were below 89 , and $50 \%$ were at or below 79; illustrating low levels of motor skill proficiency for the majority of children.

As hypothesized, there was no effect of prematurity status on overall motor skill proficiency (i.e. GMQ). Further, among the typically developing children, there were no differences for children born to fullterm compared to the children born preterm in locomotor skills, object control skills, or the stork stand times (both left and right foot). These results are quite positive. Although we do not know whether the children born prematurely had delays in motor development at birth; our results suggest that at the beginning of school (kindergarten), their skills were equivalent to the children not born prematurely. These findings are consistent with Raniero, Tudella, and Mattos (2010) who found that healthy preterm infants did not experience marked delays in motor performance.

The main effect for disability status supports our second hypothesis that children with a disability would exhibit significantly lower overall motor skill proficiency (GMQ) than children without a disability. Table 1 shows that the mean gross motor quotients for students with a disability, whether born prematurely or full term, were less than 70 (i.e. very poor). For the more specific types of skills, Table 1 shows that children living with a disability; whether born prematurely or not, had significantly lower locomotor skills than typically developing students. The children with a disability who were born full-term also displayed significantly lower object control skills than typically developing children born full-term, and the stork stand (right foot) times were significantly lower for the children with a disability born full-time compared to either group of typically developing children. Although the children with a disability who were born preterm had the lowest stork stand times (for the right foot), there were no significant differences. This lack of difference for the stork stand (right foot) is very likely due to large variance among those scores as demonstrated by the standard deviation, coupled with the very small number of children in that group. Group differences in stork stand times on the left foot were not pursued as the Kruskal-Wallis test indicated there was no overall difference. However, on the whole, our findings are consistent with other research comparing the motor skills of children with a disability and age-matched peers (Emck et al., 2009; Valentini \& Rudisill, 2004; Woodard \& Surburg, 2001) and suggest that in the motor domain, as with other domains of learning, the flow and continuity of information from parents and preschools about the child's special needs and level of functioning as she/he transitions to school is critical (Thorsen, Bø, Løge, \& Omdal, 2006).

Overall, the low motor skill scores of the children with disabilities in these inclusive classes suggest that the teachers of physical education and their assistants require training and support to meet the diverse needs of children in their first year of school. Although not the focus of this study, similar to indications from Europe (Klavina \& Kudláček, 2011), it is possible that the generalist teachers who were teaching physical education in these British Columbia schools require additional support to teach all of the children. Further research to identify the needs of these teachers is warranted. It should also be noted that two of the children with a disability had conditions that affected their ability to complete aspects of the test, that instruction and support alone would not remedy. The child with cerebral palsy had difficulty with locomotor skills in general and the child with vision impairment had difficulty catching. For these children, more tailored approaches to documenting their current motor skill status, as well as their learning and progress are needed.

Perhaps surprisingly, there was no interaction between prematurity and disability status. Examination of the mean scores in Table 1 reveal very low scores for the four children identified as being born prematurely and living with a disability. The low numbers of children in this category $(n=4)$ is a limitation of the study and likely contributed to the null effect. As we were dealing with intact inclusive classes 
of children, the proportion of children born prematurely with a disability was quite low. A further limitation of the study is that we did not stratify the sample by gender. Although the numbers of children with and without a disability who were born full-term would allow such comparisons, the other three groups were too small to subdivide by gender. A different approach, such as a case-control study, where premature children with and without a disability are identified a priori, may reveal more about the needs of these groups.

\section{Perspective}

The vast majority of the children in this study would benefit from a concentrated effort to enhance motor skills; and this was especially true for children living with a disability. To enhance access and opportunities for physical play and recreation it is important that all children lay a foundation of basic motor skills through developmentally appropriate programs that foster skilfulness and feelings of success (Robinson et al., 2015; Stodden et al., 2008). Continuity of information from preschool to school, as well as the systematic appraisal and assessment of children's motor skill proficiency at school entry, coupled with training and support of teachers, is needed. The background information and assessments would allow teachers to more specifically target instruction and the training would help teachers provide additional support in physical education as necessary.

\section{References}

Bar-Haim, Y., \& Bart, O. (2006). Motor function and social participation in kindergarten children. Social Development, 15(2), 296-310.

Bart, O., Hajami, D., \& Bar-Haim, Y. (2007). Predicting school adjustment from motor abilities in kindergarten. Infant \& Child Development, 16(6), 597-615.

Beck, S., Wojdyla, D., Say, L., Betran, A. P., Merialdi, M., Requejo, J. H., ... Van Look, P. F. A. (2010). The worldwide incidence of preterm birth: A systematic review of maternal mortality and morbidity. Bulletin of the World Health Organization, 88, 31-38.

Berger, S. E., \& Adolph, K. E. (2007). Learning and development in infant locomotion. Progress in Brain Research, 164, 237-255.

Berkeley, S. L., Zittel, L. L., Pitney, L. V., \& Nichols, S. E. (2001). Locomotor and object control skills of children diagnosed with autism. Adapted Physical Activity Quarterly, 18, 405-416.

Bruininks, R., \& Bruininks, B. (2005). Bruininks-Oseretsky Test of Motor Proficiency-2nd edition manual. Minneapolis, MN: NCS Pearson.

Crane, J. R., Naylor, P. J., Cook, R., \& Temple, V. A. (2015). Do perceptions of competence mediate the relationship between fundamental motor skill proficiency and physical activity levels of children in kindergarten? Journal of Physical Activity \& Health, 12(7), 954-961. doi: 10.1123/jpah.2013-0398 de Kieviet, J. F., Piek, J. P., Aarnoudse-Moens, C. S., \& Oosterlaan, J. (2009). Motor development in very preterm and very low-birth-weight children from birth to adolescence: A meta-analysis. Journal of the American Medical Association, 302(20), 2235-2242. doi: 10.1001/jama.2009.1708

Edwards, J., Berube, M., Erlandson, K., Haug, S., Johnstone, H., Meagher, M., ... Zwicker, J. G. (2011). Developmental coordination disorder in school-aged children born very preterm and/or at very low birth weight: A systematic review. Journal of Developmental and Behavioral Pediatrics, 32(9), 678-687. doi: 10.1097/DBP.0b013e31822a396a

Emck, C., Bosscher, R., Beek, P., \& Doreleijers, T. (2009). Gross motor performance and self-perceived motor competence in children with emotional, behavioural, and pervasive developmental disorders: A review. Developmental Medicine and Child Neurology, 51, 501-517.

Fisher, A., Reilly, J. J., Kelly, L. A., Montgomery, C., Williamson, A., Paton, J. Y., \& Grant, S. (2005). Fundamental movement skills and habitual physical activity in young children. Medicine \& Science in Sports \& Exercise, 37, 684-688.

Frey, G. C., Stanish, H., \& Temple, V. A. (2008). Physical activity of youth with intellectual disability. Review and research agenda. Adapted Physical Activity Quarterly, 25, 95-117.

Green, D., Charman, T., Pickles, A., Chandler, S., Loucas, T., Simonoff, E., \& Baird, G. (2009). Impairment in movement skills of children with autistic spectrum disorders. Developmental Medicine \& Child Neurology, 51, 311-316.

Health Canada. (2003). Canadian Perinatal Health Report. Ottawa: Minister of Public Works and Government Services Canada.

Henderson, S. E., \& Sugden, D. A. (1992). Movement Assessment Battery for Children Manual. London: The Psychological Corporation.

Huddy, C. L. J., Johnson, A., \& Hope, P. L. (2001). Educational and behavioural problems in babies of 32-35 weeks gestation. Archives of Disease in Childhood - Fetal \& Neonatal Edition, 85(1), F23-F28.

Iivonen, S., \& Sääkslahti, A. K. (2014). Preschool children's fundamental motor skills: A review of significant determinants. Early Child Development and Care, 184(7), 1107-1126. doi: 10.1080/03004430.2013.837897

Katz-Leurer, M., Rotem, H., Keren, O., \& Meyer, S. (2009). Balance abilities and gait characteristics in post-traumatic brain injury, cerebral palsy and typically developed children. Developmental Neurorehabilitation, 12, 100-105.

Kershaw, P., Irwin, L., Trafford, K., \& Hertzman, C. (2005). The British Columbia atlas of child development. Georgetown, ON: Human Early Learning Partnership.

Kerstjens, J. M., de Winter, A. F., Bocca-Tjeertes, I. F., ten Vergert, E. M. J., Reijneveld, S. A., \& Bos, A. F. (2011). Developmental delay in moderately preterm-born children at school entry. Journal of Pediatrics, 159(1), 92-98.

Klavina, A., \& Kudláček, M. (2011). Physical education for students with special education needs in Europe: Findings of the EUSAPA project. European Journal of Adapted Physical Activity, 4(2), 46-62.

Langley, R. (1979). Practical Statistics Simply Explained. London: Pan Books. 
Lawn, J. E., Gravett, M. G., Nunes, T. M., Rubens, C. E., \& Stanton, C. (2010). Global report on preterm birth and stillbirth (1 of 7): Definitions, description of the burden and opportunities to improve data. BMC Pregnancy \& Childbirth, 10, 1-22.

LeGear, M., Greyling, L., Sloan, E., Bell, R., Williams, B., Naylor, P., \& Temple, V. A. (2012). A window of opportunity? Motor skills and perceptions of competence of children in Kindergarten. The International Journal of Behavioral Nutrition and Physical Activity, 9, 29-34.

Majnemer, A., Shevell, M., Law, M., Birnbaum, R., Chilingaryan, G., Rosenbaum, P., \& Poulin, C. (2008). Participation and enjoyment of leisure activities in school-aged children with cerebral palsy. Developmental Medicine \& Child Neurology, 50, 751-758. doi: 10.1111/j.1469-8749.2008.03068.x

Manjiviona, J., \& Prior, M. (1995). Comparison of asperger syndrome and high-functioning autistic children on a test of motor impairment. Journal of Autism \& Developmental Disorders, 25, 23-39.

Margetts, K. (2002). Transition to school - Complexity and diversity. European Early Childhood Education Research Journal, 10(2), 103-114. doi: 10.1080/13502930285208981

Murphy, N., \& Carbone, P. (2008). Promoting the participation of children with disabilities in sports, recreation, and physical activities. Pediatrics, 121, 1057-1061.

Payne, G. V., \& Issacs, L. D. (2008). Human motor development. A lifespan approach (7th ed.). Boston: McGraw Hill.

Provost, B., Heimerl, S., \& Lopez, B. R. (2007). Levels of gross and fine motor development in young children with autism spectrum disorder. Physical \& Occupational Therapy in Pediatrics, 27, 21-36.

Raniero, E. P., Tudella, E., \& Mattos, R. S. (2010). Pattern and rate of motor skill acquisition among preterm infants during the first four months corrected age. Revista Brasileira de Fisioterapia, 4, 396-403.

Rarick, G. L. (1980). Cognitive-motor relationships in the growing years. Research Quarterly for Exercise \& Sport, 51, 174-192.

Rimmer, J. H., \& Rowland, J. L. (2008). Physical activity for youth with disabilities: A critical need in an underserved population. Developmental Neurorehabilitation, 11, 141-148.

Robinson, L. E., Stodden, D. F., Barnett, L. M., Lopes, V. P., Logan, S. W., Rodrigues, L. P., \& D'Hondt, E. (2015). Motor competence and its effect on positive developmental trajectories of health. Sports Medicine, 45(9), 1273-1284. doi: 10.1007/s40279-015-0351-6

Rudisill, M. E., Adalbjornsson, C. F., Howard, C. H., Lehman, D., Wiley, P., Martin, E. H., ... Valentini, N. C. (2001). Mastery motivational climate interventions and motor skill performance: Gender issues. Journal of Sport \& Exercise Psychology, 23, S55.

Salkind, N. J., \& Rasmussen, K. (2007). Kruskal-Wallis OneWay Analysis of Variance. In N. J. Salkind (Ed.), Encyclopedia of Measurement and Statistics (Vol. 2, pp. 519-521). Thousand Oaks, CA: SAGE Reference.

Shikako-Thomas, K., Majnemer, A., Law, M., \& Lach, L. (2008). Determinants of participation in leisure activities in children and youth with cerebral palsy: Systematic review. Physical \& Occupational Therapy in Pediatrics, 28, $155-169$.
Simons, J., Daly, D., Theodorou, F., Caron, C., Simons, J., \& Andoniadou, E. (2008). Validity and reliability of the TGMD-2 in 7-10-year-old Flemish children with intellectual disability. Adapted Physical Activity Quarterly, 25, $71-82$.

SPSS Inc. (2013). IBM SPSS Statistics (Version 22). NY: Somers.

Steele, C., Kalnins, I., Jutai, J., Stevens, S., Bortolussi, J., \& Biggar, W. (1996). Lifestyle health behaviors of 11- to 16-year-old youth with physical disabilities. Health Education Research, 11, 173-186.

Stephens, B. E., \& Vohr, B. R. (2009). Neurodevelopmental outcome of the premature infant. Pediatric Clinics of North America, 56(3), 631-646. doi: 10.1016/j.pcl.2009.03.005

Stodden, D. F., Goodway, J. D., Langendorfer, S. J., Roberton, M. A., Rudisill, M. E., Garcia, C., \& Garcia, L. E. (2008). A developmental perspective on the role of motor skill competence in physical activity: An emergent relationship. Quest, 60(2), 290-306.

Temple, V. A., Crane, J. R., Brown, A., Williams, B., \& Bell, R. I. (2016). Relationships between recreational pursuits and motor skills in young children. Physical Education and Sport Pedagogy, 21(3), 268-280. doi: 10.1080/17408989.2014.924494

Thorsen, A. A., Bø, I., Løge, I. K., \& Omdal, H. (2006). Transition from day-care centres to school: What kind of information do schools want from day-care centres and parents, and what kind of information do the two parties want to give schools? European Early Childhood Education Research Journal, 14(1), 77-90. doi: 10.1080/13502930685209821

Ulrich, D. A. (2000). Test of Gross Motor Development (TGMD-2) (2nd ed.). Austin, TX: PRO-ED, Inc.

Valentini, N., \& Rudisill, M. (2004). Motivational climate, motor-skill development, and perceived competence: Two studies of developmentally delayed kindergarten children. Journal of Teaching in Physical Education, 23, 216-234.

Westendorp, M., Houwen, S., Hartman, E., \& Visscher, C. (2011). Are gross motor skills and sports participation related in children with intellectual disabilities? Research in Developmental Disabilities, 32(3), 1147-1153. doi: http://dx.doi. org/10.1016/j.ridd.2011.01.009

Williams, H. G., Pfeiffer, K. A., O’Neill, J. R., Dowda, M., McIver, K. L., Brown, W. H., \& Pate, R. R. (2008). Motor skill performance and physical activity in preschool children. Obesity, 16, 1421-1426.

Wocadlo, C., \& Rieger, I. (2008). Motor impairment and low achievement in very preterm children at eight years of age. Early Human Development, 84(11), 769-776.

Woodard, R., \& Surburg, P. (2001). The performance of fundamental movement skills by elementary school children with learning disabilities. Physical Educator, 58, 198-206.

Zarrett, N., Fay, K., Li, Y., Carrano, J., Phelps, E., \& Lerner, R. M. (2009). More than child's play: Variable- and pattern-centered approaches for examining effects of sports participation on youth development. Developmental Psychology, 45(2), 368-382. doi: 10.1037/a0014577

\section{Corresponding author}

Viviene Anne Temple

Email address | vtemple@uvic.ca 